\title{
Hypoxia modulates the stem cell population and induces EMT in the MCF-10A breast epithelial cell line
}

\author{
CARL S. DALY $^{1}$, ARWA FLEMBAN ${ }^{1,2}$, MAI SHAFEI $^{1}$, MYRA E. CONWAY $^{1}$, \\ DAVID QUALTROUGH ${ }^{1}$ and SARAH J. DEAN ${ }^{1}$ \\ ${ }^{1}$ Department of Applied Sciences, Faculty of Health and Applied Sciences, University of West of England, \\ Bristol, BS16 1QY, UK; ${ }^{2}$ Department of Pathology, Faculty of Medicine, \\ Umm Al-Qura University, Makkah 24382, Saudi Arabia
}

Received July 3, 2017; Accepted October 31, 2017

DOI: $10.3892 /$ or.2017.6125

\begin{abstract}
A common feature among pre-malignant lesions is the induction of hypoxia through increased cell propagation and reduced access to blood flow. Hypoxia in breast cancer has been associated with poor patient prognosis, resistance to chemotherapy and increased metastasis. Although hypoxia has been correlated with factors associated with the latter stages of cancer progression, it is not well documented how hypoxia influences cells in the earliest stages of transformation. Using the immortalized MCF-10A breast epithelial cell line, we used hypoxic culture conditions to mimic reduced $\mathrm{O}_{2}$ levels found within early pre-malignant lesions and assessed various cellular parameters. In this non-transformed mammary cell line, $\mathrm{O}_{2}$ deprivation led to some changes not immediately associated with cancer progression, such as decreased proliferation, cell cycle arrest and increased apoptosis. In contrast, hypoxia did induce other changes more consistent with an increased metastatic potential. A rise in the $\mathrm{CD} 44^{+} \mathrm{CD} 24$ / low-labeled cell sub-population along with increased colony forming capability indicated an expanded stem cell population. Hypoxia also induced cellular and molecular changes consistent with an epithelial-to-mesenchymal transition (EMT). Furthermore, these cells now exhibited increased migratory and invasive abilities. These results underscore the contribution of the hypoxic tumour microenvironment in cancer progression and dissemination.
\end{abstract}

\section{Introduction}

Breast cancer is the most common malignancy in woman worldwide, and the second leading cause of cancer-related deaths in females (1). Considering that metastasis is responsible

Correspondence to: Dr Carl S. Daly, Department of Applied Sciences, Faculty of Health and Applied Sciences, Frenchay Campus, Coldharbour Lane, Bristol, BS16 1QY, UK

E-mail: carl.daly@uwe.ac.uk

Key words: breast, cancer, stem cells, hypoxia, MCF-10A, EMT for $90 \%$ of these deaths (2), understanding the mechanisms which contribute to this endpoint is fundamental in the design of treatment strategies to alleviate breast cancer mortality. The pathological progression of breast cancer is well documented (3). However, the factors which govern this progression are less characterized (4). Considerable attention has been paid to the contribution of somatic mutation and epigenetic alterations in cancer initiation and progression (5-7). However, the role of tumour-associated microenvironmental changes may be equally contributive and are only recently gaining impetus (8).

Hypoxia exemplifies one microenvironmental change associated with tumourigenesis. In the earliest stages of tumour development, abnormal proliferation and accumulation of cells can lead to increased cellular mass, elevated intra-tissue pressure, insufficient perfusion and subsequent $\mathrm{O}_{2}$ deficiency (9). In breast cancer patients, intra-tumour measurements conducted in situ have revealed substantial levels of $\mathrm{O}_{2}$ deprivation compared to normal breast tissue (10). Hypoxia in breast cancer has been associated with poor patient prognosis $(11-13)$, resistance to chemotherapy $(14,15)$ and increased metastasis $(13,16,17)$.

How hypoxia influences cancer progression is not fully defined. It is known that cells respond to reduced $\mathrm{O}_{2}$ availability by increasing the activity of hypoxia-inducible factors (HIF-1 $\alpha$ and HIF-2 $\alpha$ ) which, in turn, mediate global transcriptional changes (18). These transcriptional changes involve many genes and may alter various cellular processes which contribute to cancer progression (18). Numerous studies connecting hypoxia and cancer have been conducted on transformed cells isolated from animal models, patient tumours and established cancer cell lines (19). However, these cells harbour many cancer-associated genetic and epigenetic changes. How hypoxia affects breast epithelial cells in the earlier stages of transformation remains less well defined.

In the present study, we used the untransformed MCF-10A breast epithelial cell line and hypoxic culture conditions to replicate conditions found within early hyperplastic breast lesions. Using this model we were able to study the effects of $\mathrm{O}_{2}$ deprivation independent from the contribution of cancerassociated genetic and epigenetic changes. We demonstrated that reduced $\mathrm{O}_{2}$ availability induced a number of changes consistent with increased metastatic potential. Proliferation and 
cell cycle progression were perturbed along with an increase in apoptosis. A rise in the $\mathrm{CD} 44^{+} \mathrm{CD} 24$ / low cells coupled with an increased colony forming ability indicated a rise in the stem cell population. Cells underwent cellular and molecular changes consistent with epithelial-to-mesenchymal transition (EMT). Furthermore, hypoxia increased the migratory and invasive capabilities of these cells. Collectively, these results highlight the contribution of hypoxic microenvironmental changes in cancer progression and dissemination.

\section{Materials and methods}

Human tissue samples and ethics statement. Surplus breast tissue initially removed surgically for diagnostic purposes was used in the present study following informed patient consent. Archived paraffin-embedded tissue was obtained from Bristol Royal Infirmary under ethical approval from the NHS Health Research Authority and UWE Ethics Committee (Ref. 11/SW/0127). All methods were performed in accordance with the NHS Health Research Authority guidelines and regulations.

Cell culture and hypoxia. MCF-10A cells were purchased from the American Tissue Culture Collection (ATCC; Manassas, VA, USA) and cultured in Dulbecco's modified Eagle's medium/Nutrient Mixture F-12 Ham supplemented with $100 \mathrm{ng} / \mathrm{ml}$ cholera toxin (Sigma, St. Louis, MO, USA), $20 \mathrm{ng} / \mathrm{ml}$ epidermal growth factor (EGF) (Thermo Fisher Scientific, Inc., Waltham, MA, USA), $10 \mu \mathrm{g} / \mathrm{ml}$ insulin, $500 \mathrm{ng} / \mathrm{ml}$ hydrocortisone and 5\% heat-inactivated horse serum (all from Sigma). Experiments were conducted in the aforementioned media mixture excluding EGF (media was replaced at least $24 \mathrm{~h}$ before experiments). MCF-10A cells were subjected to no $>8$ passages in culture before experiments. Whilst control cells were incubated at $37^{\circ} \mathrm{C}$ in a humidified atmosphere containing $5 \% \mathrm{CO}_{2}$ and $21 \% \mathrm{O}_{2}$ (termed normoxia), hypoxic conditions (termed hypoxia) were induced using an airtight modular incubator chamber (Billups-Rothenberg, Inc., San Diego, CA, USA). Briefly, the cells were sealed in the modular incubator chambers with a sterile phosphate-buffered saline (PBS) reserve to maintain humidity, and then purged with a reduced $\mathrm{O}_{2}$ gas mixture $\left(1 \% \mathrm{O}_{2}, 5 \% \mathrm{CO}_{2}\right.$ and $\left.94 \% \mathrm{~N}_{2}\right)$. The chamber was then sealed and placed in an incubator at $37^{\circ} \mathrm{C}$ for $72 \mathrm{~h}$.

Immunofluorescence microscopy. Paraffin blocks containing embedded human breast tissue were sectioned at $4 \mu \mathrm{m}$ using a microtome (Leica RM2235) and mounted on Superfrost Plus slides (Thermo Fisher Scientific, Inc.). Sections were then deparaffinized with Histoclear (National Diagnostics, Atlanta, GA, USA) and rehydrated using a series of ethanol concentrations and $\mathrm{dH}_{2} \mathrm{O}$. Antigen unmasking was performed by heating in citrate buffer ( $\mathrm{pH}$ 6.0) using a water bath for $30 \min \left(95-100^{\circ} \mathrm{C}\right)$ and then allowing the sections to cool to room temperature (RT) in the buffer. Cultured MCF-10A cells were fixed with ice cold $4 \%$ paraformaldehyde for $20 \mathrm{~min}$ and then stored at $4^{\circ} \mathrm{C}$ in $70 \%$ ethanol. The slides and/or fixed cells were incubated in blocking serum [goat serum (Vector Laboratories, Burlingame, CA, USA) diluted in Tris-buffered saline (TBS)] for $30 \mathrm{~min}$ at RT, and then incubated in a primary antibody overnight at $4^{\circ} \mathrm{C}$. Antibodies used were anti-human and are as follows: CA IX (1:20; a kind gift from Professor M. Ladomery), Ki-67 (RM-9106-S, 1:50; Thermo Fisher Scientific, Inc.), cleaved caspase-3 (9661s, 1:200; Cell Signaling Technology, Inc., Beverly, MA, USA), E-cadherin (610181, 1:200), $\beta$-catenin $(610153,1: 200)$ and vimentin (550513, 1:100) (all from BD Biosciences, Franklin Lakes, NJ, USA). The following day, the slides and/or cells were washed in TBS and then incubated with suitable fluorescent-labelled secondary antibodies [Alexa Fluor-conjugated secondary antibodies (A1101/A11008/A11005, 1:200; Thermo Fisher Scientific, Inc.)] for $1 \mathrm{~h}$ at RT. Subsequently, the slides and/or cells were washed with TBS, then mounted using Vectashield Hardset Mounting Media with 4,6-diamidino-2-phenylindole (DAPI) (Vector Laboratories). All images were obtained using a fluorescence microscope (Nikon Eclipse 80i).

Western blot analyses. Cells were harvested in lysis buffer (10 mM Tris- $\mathrm{HCl}, 50 \mathrm{mM}$ sodium chloride, $5 \mathrm{mM}$ EDTA, $15 \mathrm{mM}$ sodium pyrophosphate, $50 \mathrm{mM}$ sodium fluoride and $100 \mu \mathrm{M}$ sodium orthovanadate) supplemented with phosphatase (Roche Applied Science, Indianapolis, IN, USA) and protease (Sigma) inhibitor cocktails at $4^{\circ} \mathrm{C}$ for $30 \mathrm{~min}$. Following collection, the cells were sonicated on ice using Soniprep 150 (MSE Ltd., London, UK), then centrifuged at $15,000 \mathrm{x} \mathrm{g}$ for $15 \mathrm{~min}$ at $4^{\circ} \mathrm{C}$ and then the supernatant was collected. The protein concentration was determined using a Coomassie (Bradford) protein assay kit (Thermo Fisher Scientific, Inc.). An equal amount of protein from each sample was separated using $10 \%$ sodium dodecyl sulfatepolyacrylamide gel electrophoresis (SDS-PAGE) gel and transferred onto a nitrocellulose membrane (GE Healthcare, Little Chalfont, UK). After blocking with 5\% milk powder for $1 \mathrm{~h}$ at room temperature, the membranes were incubated in a primary antibody overnight at $4^{\circ} \mathrm{C}$. The antibodies used were anti-human and are as follows: CA IX (1:20; a gift from Professor M. Ladomery), E-cadherin (610181, 1:2,000), $\beta$-catenin (610153, 1:2,000), vimentin (550513, 1:1,000) (all from BD Biosciences) and $\beta$-actin (MA1-140, 1:10,000; Thermo Fisher Scientific, Inc.) which was used as a loading control. The blot membrane was washed, then incubated with horseradish peroxidase-conjugated secondary antibodies (PI-1000/PI-2000, 1:2,000-1:5,000; Vector Laboratories), and signals were revealed using a chemiluminescence kit (Thermo Fisher Scientific, Inc.).

Proliferation and apoptosis scoring. Proliferation and apoptosis were assessed as a percentage of $\mathrm{Ki}$-67-positive cells and a percentage of cleaved caspase-3-positive cells, respectively. Briefly, 10 evenly distributed x40 fields of view were imaged using a fluorescence microscope (Nikon Eclipse 80i) for each independent group. Positively-labeled cells were counted and scored as a percentage of total cells. Experiments were performed at least in triplicate for each group.

Flow cytometry. Cells were washed once with Hanks' balanced salt solution (HBSS) (Thermo Fisher Scientific, Inc.), and then harvested with $0.05 \%$ trypsin/0.025\% EDTA (Thermo Fisher Scientific, Inc.). Detached cells were washed with HBSS containing 2\% horse serum (Sigma) (wash buffer), and re-suspended in the wash buffer $\left(10^{6}\right.$ cells $\left./ 100 \mu \mathrm{l}\right)$. Anti-human 
CD24-FITC-conjugated (560992, 1:25; BD Biosciences) and anti-human CD44-APC-conjugated (103012, 1:25; BioLegend, Inc., San Diego, CA, USA) antibodies or the respective isotype controls were added to the cell suspension, as recommended by the manufacturer, and incubated at $4^{\circ} \mathrm{C}$ in the dark for $30 \mathrm{~min}$. Subsequently, the labelled cells were washed in wash buffer and then analysed on an Accuri C6 cytometer using CFlow Plus software (both from BD Biosciences).

Cell cycle analysis. Cells were harvested, washed with ice-cold PBS, and then fixed in $70 \%$ ethanol for at least $30 \mathrm{~min}$ at $4{ }^{\circ} \mathrm{C}$. Before analysis, the cells were washed again in PBS, then incubated in staining buffer [100 $\mu \mathrm{g} / \mathrm{ml}$ RNase and $50 \mu \mathrm{g} / \mathrm{ml}$ propidium iodide (PI) (Sigma)] in the dark at $4^{\circ} \mathrm{C}$ for $30 \mathrm{~min}$. The samples were analysed by flow cytometry using an Accuri C6 cytometer (BD Biosciences). CFlow plus software (BD Biosciences) was used to calculate the percentage of cells in the $\mathrm{G} 0 / \mathrm{G} 1, \mathrm{~S}$ and $\mathrm{G} 2 / \mathrm{M}$ phases. All studies were performed in triplicate.

Mammosphere forming assay. Six-well culture plates were coated with poly(2-hydroxyethyl methacrylate) (Santa Cruz Biotechnology, Santa Cruz, CA, USA) to obtain an ultralow adhesion surface. Following treatment, the cells were trypsinized and mechanically disrupted to obtain single-cell suspensions. The single-cell suspensions were then plated at $1 \times 10^{3}$ in $1 \mathrm{ml}$ MCF-10A medium in the ultra-low adhesion wells. The cells were left to form spheres for 10 days, and mammospheres were considered cell aggregates $>50 \mu \mathrm{m}$ in diameter. The mammospheres were imaged, counted and measured using a phase-contrast inverted microscope (Nikon Eclipse TE300). Each experiment was repeated in triplicate.

Wound healing assay. Cells were plated in 6-well culture plates, and wounds were inflicted upon the cell monolayers using a sterile plastic $200-\mu 1$ micropipette tip. Phase-contrast microscopy images were immediately obtained after wounding and again $48 \mathrm{~h}$ later using an inverted microscope (Nikon Eclipse TE300). The experiments were independently performed in triplicate, and the migration distance under each condition was assessed by analyzing the images using ImageJ software (National Institutes of Health, Rockville, MD, USA).

Transwell invasion assay. Transwell inserts (Millipore, Billerica, MA, USA) containing polycarbonate filters with $8-\mu \mathrm{m}$ pores were used in the assay. The inserts were coated with $50 \mu \mathrm{l}$ of Matrigel matrix $(1 \mathrm{mg} / \mathrm{ml})$ according to the manufacturer's recommendations (Thermo Fisher Scientific, Inc.). The cells were seeded in the upper chambers of the inserts at a density of $2 \times 10^{5}$ cells in $1 \mathrm{ml}$ serum-free MCF-10A medium. MCF-10A medium $(2 \mathrm{ml})$ containing serum was placed in the lower chambers. Following $72 \mathrm{~h}$ of treatment, the cells on the upper surface of the membrane were removed using a methanol coated cotton swab. The cells on the lower chamber were fixed in $4 \%$ paraformaldehyde and stained with hematoxylin (Sigma). For each membrane, the number of cells was counted in 10 evenly distributed $\mathrm{x} 40$ fields of view using a light microscope (Nikon Eclipse 80i). Each experiment was repeated in triplicate.
Statistical analysis. Data for each group are presented as the mean \pm SD. Statistical analyses were performed using SPSS for Windows, version 20.0 (IBM SPSS, Inc., Chicago, IL, USA). Values of $\mathrm{P}<0.05$ were deemed statistically significant.

\section{Results}

Hypoxic conditions induce upregulation of carbonic anhydrase IX (CAIX). CA IX is a downstream target of HIF- $1 \alpha$ and a robust marker of hypoxia (20). To assess the consequence of abnormal breast cell propagation on intracellular $\mathrm{O}_{2}$ levels, sections of hyperplastic breast tissue were labeled for CA IX and compared to control tissue (Fig. 1A). Whilst CA IX expression was undetectable in control tissue, upregulation was prominent within hyperplastic tissue with the highest expression observed within the center of lesions corresponding to areas with the most limited access to blood supply.

To model hypoxic conditions found within the breast tumour microenvironment and delineate associated consequences, MCF-10A cells were cultured in hypoxic conditions $\left(1 \% \mathrm{O}_{2}\right)$ for $72 \mathrm{~h}$ and compared to cells cultured in normoxia $\left(21 \% \mathrm{O}_{2}\right)$. Previous studies have suggested a level of $\sim 1 \% \mathrm{O}_{2}$ is found within the breast tumour microenvironment (21). Whilst control MCF-10A cells cultured in normoxia displayed undetectable levels of CA IX expression, MCF-10A cells cultured under hypoxic conditions displayed an increase in CA IX expression detected by both fluorescence microscopy (Fig. 1B) and western blot analysis (Fig. 1C).

Hypoxia reduces proliferation, induces apoptosis and perturbs cell cycle progression. Increased cell division and evasion of cell death are both prominent features in most tumours (22). To assess the effects of hypoxia on cell division, proliferation was analysed by monitoring changes in Ki-67 expression (Fig. 2A). A statistically significant reduction in the percentage of Ki-67 positive cells was observed in MCF-10A cells cultured under hypoxic conditions in comparison to those cultured in normoxia $(2.50 \pm 1.28$ compared to $29.53 \pm 3.89 \%$ respectively; $\mathrm{P}<0.05$ ) (Fig. 2B). To assess the effects of hypoxia on cell death, apoptosis was analysed using cleaved caspase-3 expression (Fig. 2C). A statistically significant increase in the percentage of cleaved caspase-3 positive cells was observed in MCF-10A cells cultured under hypoxic conditions compared with those cultured in normoxia $(3.91 \pm 1.12$ compared to $0.35 \pm 0.18 \%$ respectively; $\mathrm{P}<0.05$ ) (Fig. 2D).

Given the decrease in proliferation and increase in apoptosis in MCF-10A cells cultured in hypoxia and the link between these parameters and cell cycle progression, cell cycle distribution analysis was performed using PI staining and flow cytometry (Fig. 2E). 'Gating' was performed in analyses to include live cells in the $\mathrm{G} 0 / \mathrm{G} 1, \mathrm{~S}$ or G2/M phases whilst excluding debris and/or necrotic cells. MCF-10A cells cultured in normoxia had the following distribution: G0/G1 phase, $74.27 \pm 0.81 \%$; S phase, $5.63 \pm 0.32 \%$; and $\mathrm{G} 2 / \mathrm{M}$ phase, $18.57 \pm 1.30 \%$, whilst MCF-10A cells cultured in hypoxia had this distribution: G0/G1 phase, $63.83 \pm 1.63 \%$; S phase, $3.33 \pm 0.25 \%$; and $\mathrm{G} 2 / \mathrm{M}$ phase, $32.40 \pm 3.15 \%$. As shown in Fig. 2F, MCF-10A cells cultured in hypoxic conditions had a statistically significant decrease in the percentage of cells in the $\mathrm{G} 0 / \mathrm{G} 1$ and $\mathrm{S}$ phases $(\mathrm{P}<0.05)$, compared to MCF-10A cells 


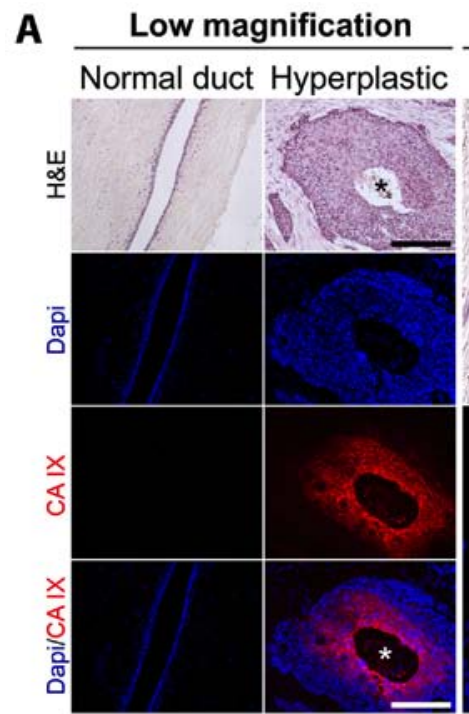

B

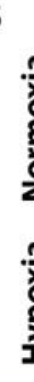

High magnification

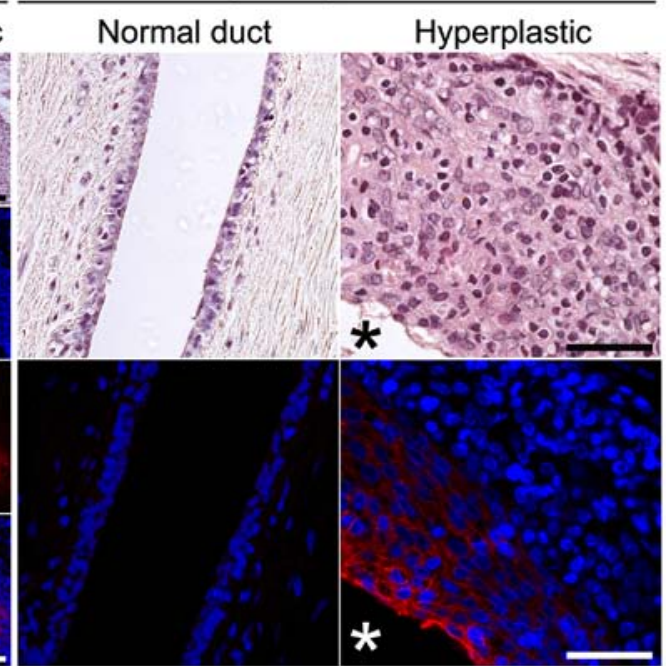

C

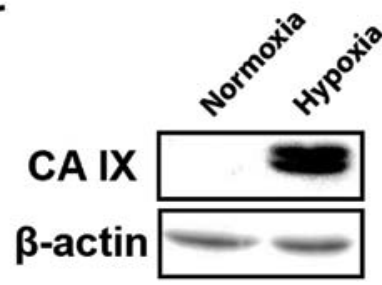

Figure 1. CA IX expression marks hypoxia in human breast tissue. (A) Serial sections of human breast tissue were stained with H\&E or labeled for CA IX using fluorescent immunohistochemistry (scale bar represents $200 \mu \mathrm{m}$ in low magnification; $50 \mu \mathrm{m}$ in high magnification; ${ }^{*}$ denotes the region furthest away from blood supply). (B) MCF-10A cells were placed in $20 \% \mathrm{O}_{2}$ or $1 \% \mathrm{O}_{2}$ culture conditions for $72 \mathrm{~h}$ then labeled for CA IX using fluorescent immunohistochemistry (scale bar represents $10 \mu \mathrm{m}$ ). (C) The expression levels of CA IX in MCF-10A cells were detected by western blotting, $\beta$-actin served as a loading control.
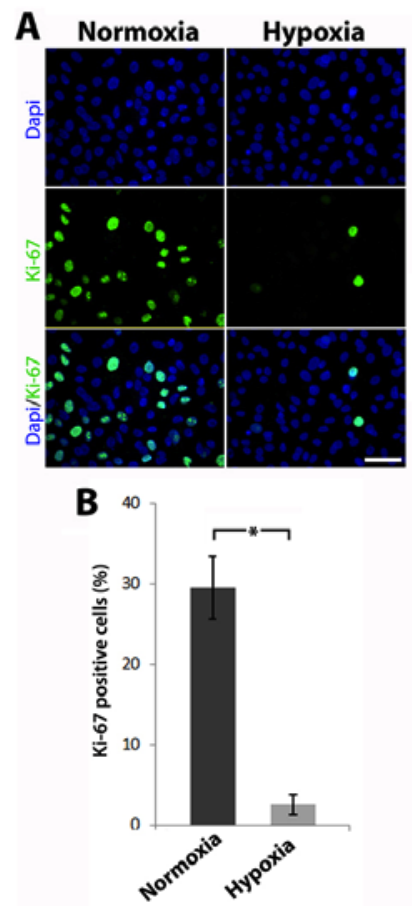
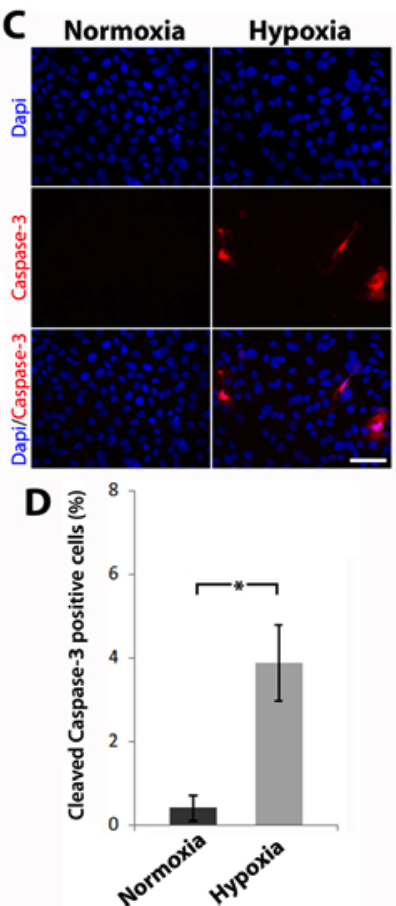
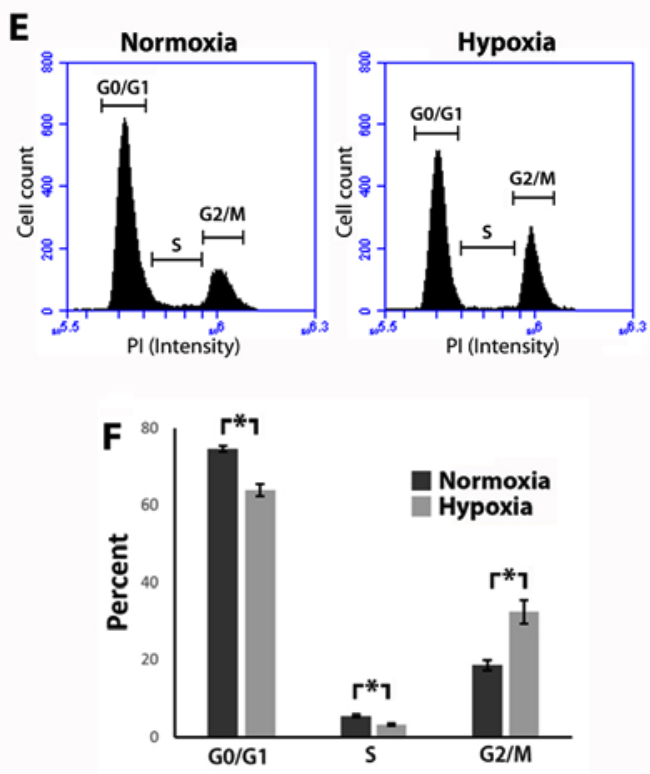

Figure 2. Hypoxia reduces proliferation, perturbs cell cycle progression and induces apoptosis. (A) Cells were labeled for Ki-67 using fluorescent immunohistochemistry (scale bar, $25 \mu \mathrm{m}$ ). (B) Percentage of Ki-67 positive cells (error bars \pm standard deviation, ${ }^{*} \mathrm{P} \leq 0.05$, Mann-Whitney $\mathrm{U}$ test, $\mathrm{n} \geq 3$ ). (C) Cells were labeled for cleaved caspase-3 using fluorescent immunohistochemistry (scale bar, $25 \mu \mathrm{m}$ ). (D) Percentage of cleaved caspase-3 positive cells (error bars \pm standard deviation, "P $\leq 0.05$, Mann-Whitney $\mathrm{U}$ test, $\mathrm{n} \geq 3$ ). (E) Cell cycle distribution was evaluated using flow cytometry. (F) Graph displays the cell cycle phase expressed as a percentage of total cells (error bars \pm standard deviation, ${ }^{*} \mathrm{P} \leq 0.05$, Mann-Whitney $\mathrm{U}$ test, $\mathrm{n} \geq 3$ ). 
A

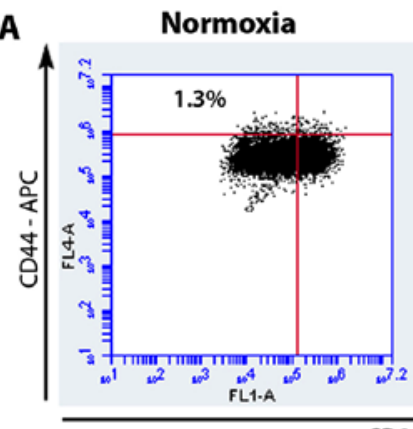

Hypoxia

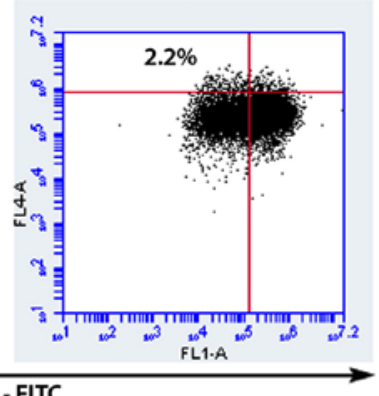

B

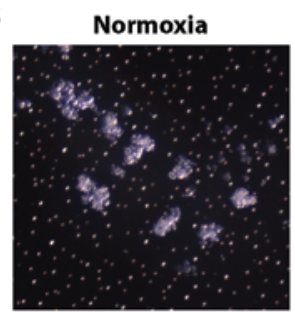

Hypoxia

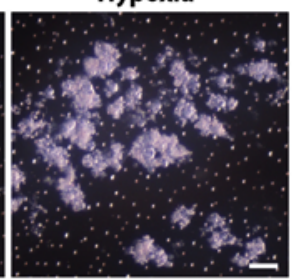

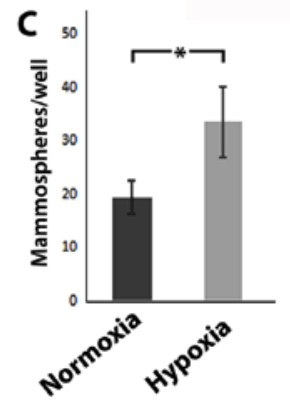

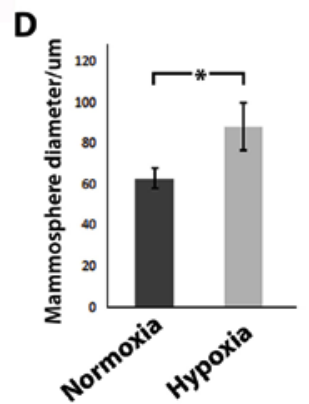

Figure 3. Hypoxia increases the stem/progenitor cell population. (A) Flow cytometric analysis of CD44 and CD24 cell surface markers. Percentage of CD $44^{+} \mathrm{CD} 24 /$ low stained cells displayed. (B) Photomicrographs of mammospheres formed after 7 days (scale bar represents $100 \mu \mathrm{m}$ ). (C) Average number of mammospheres formed/well (error bars \pm standard deviation, ${ }^{*} \mathrm{P} \leq 0.05$, Mann-Whitney $\mathrm{U}$ test, $\mathrm{n} \geq 3$ ). (D) Average size of formed mammospheres (error bars \pm standard deviation, ${ }^{*} \mathrm{P} \leq 0.05$, Mann-Whitney $\mathrm{U}$ test, $\mathrm{n} \geq 3$ ).

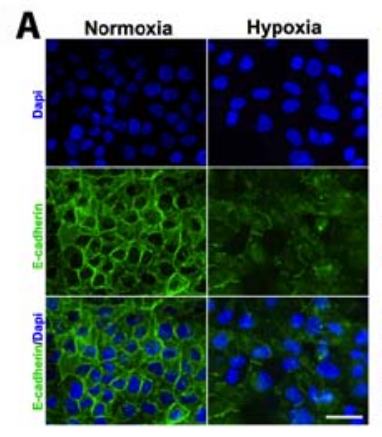

C

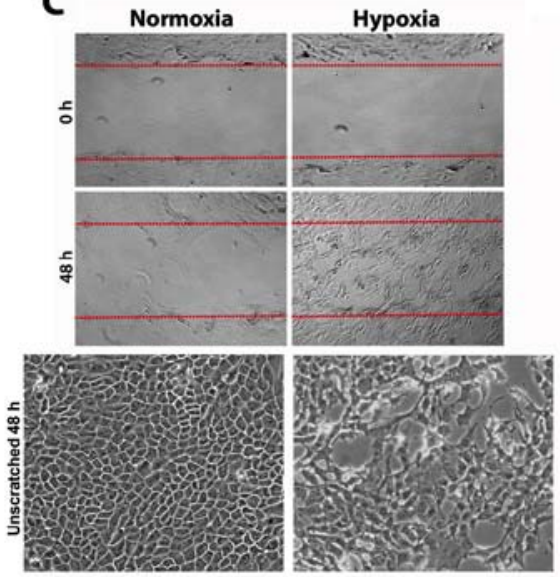

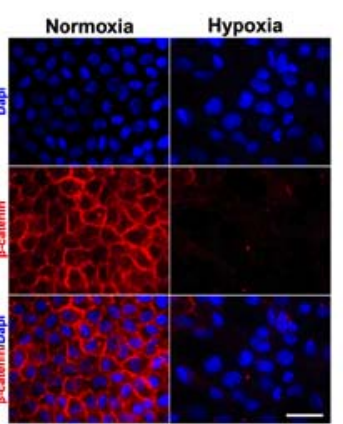

D

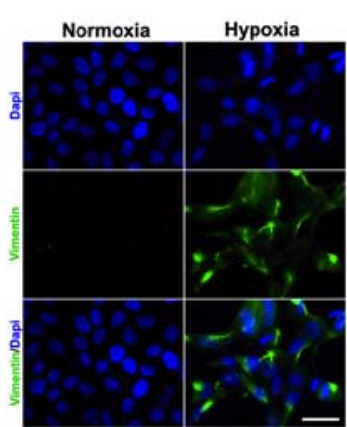

$\mathbf{F}$
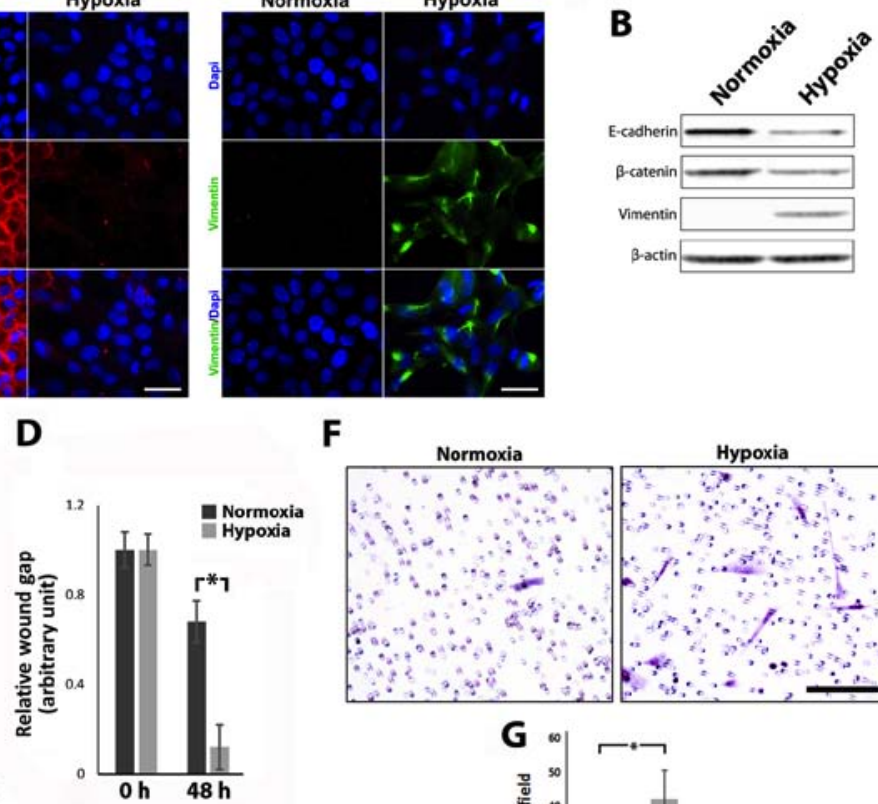

$\mathbf{E}$
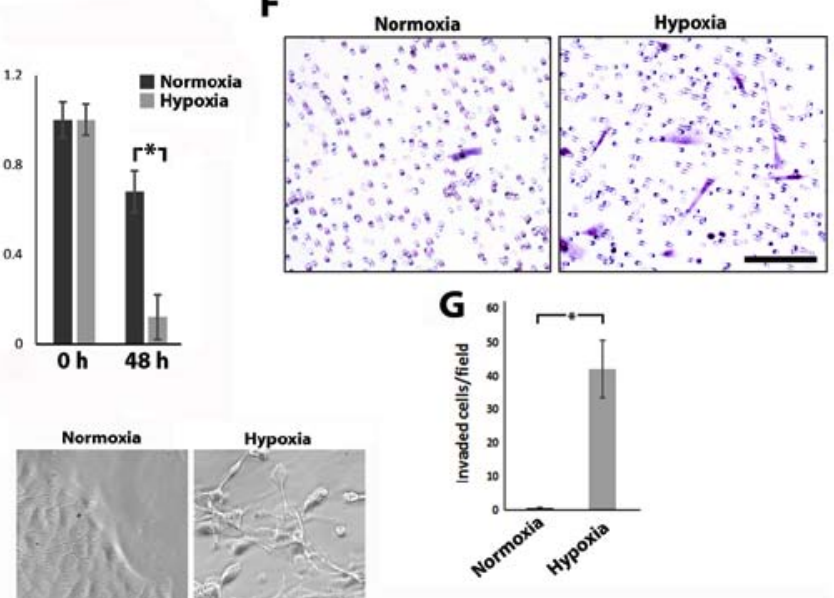

Figure 4. Hypoxia induces EMT, increased migration and invasion. (A) Cells were labeled for E-cadherin, $\beta$-catenin and vimentin using fluorescent immunohistochemistry (scale bar, $25 \mu \mathrm{m}$ ). (B) The levels of protein expression of E-cadherin, $\beta$-catenin and vimentin were detected by western blotting, $\beta$-actin served as a loading control. (C) Scratch wound migration assays were performed on confluent cells. Red dotted lines indicate the wound borders at the beginning of the assay. Lower panel displays comparative unscratched area. (D) Relative wound gap calculated as a ratio of the remaining wound gap at $48 \mathrm{~h}$ and the original wound gap at $0 \mathrm{~h}$ (error bars \pm standard deviation, ${ }^{*} \mathrm{P} \leq 0.05$; Mann-Whitney $\mathrm{U}$ test, $\mathrm{n} \geq 3$ ). (E) Phase contrast images of migratory leading edge. (F) Photomicrographs of invaded cells in Matrigel Transwell assay. (G) Average number of invaded cells/field of view (error bars \pm standard deviation, ${ }^{*} \mathrm{P} \leq 0.05$; Mann-Whitney U test, $\mathrm{n} \geq 3$ ). 
cultured in normoxia. Conversely, a statistically significant increase in the percentage of cells in the $\mathrm{G} 2 / \mathrm{M}$ phase $(\mathrm{P}<0.05)$ was observed in MCF-10A cells cultured in hypoxia compared to MCF-10A cells cultured in normoxia. Collectively, these data revealed that hypoxia can regulate cell growth and can block cell cycle progression in the $\mathrm{G} 2 / \mathrm{M}$ phase.

Hypoxia increases the stem cell population. Previous studies have utilized the cell surface markers CD44 and CD24 to distinguish a $\mathrm{CD} 44^{+} \mathrm{CD} 24$ / low sub-population which is enriched for stem cells/cancer stem cells $(23,24)$. Using flow cytometric analysis (Fig. 3A), we revealed that MCF-10A cells cultured under hypoxic conditions displayed a higher percentage of cells in the $\mathrm{CD} 44^{+} \mathrm{CD} 24$ /low sub-population in comparison to MCF-10A cells cultured in normoxia (2.2\% in comparison to $1.3 \%$, respectively). Mammosphere assays have been previously used as a surrogate reporter of stem cell activity $(25,26)$, and an increase in the number and/or size of formed colonies are indicative of an expanded stem cell population. MCF-10A cells grown in normoxia or hypoxia were seeded in low adhesion culture vessels, left to form spheres in normoxia and then compared (Fig. 3B). Following re-oxygenation, MCF-10A cells cultured in hypoxia displayed a statistically significant increase in both mammosphere forming efficiency (33.50 $\pm 6.56 /$ well compared to $19.50 \pm 3.11 /$ well, respectively; $\mathrm{P}<0.05$ ) (Fig. 3C) and mammosphere size $(88.78 \pm 11.57$ compared to $63.49 \pm 4.77 \mu \mathrm{m}$ respectively, $\mathrm{P}<0.05$ ) (Fig. 3D) in comparison to MCF-10A cells initially cultured in normoxia. Collectively, these results suggest that hypoxic conditions lead to an expansion of the stem cell population.

Hypoxia induces EMT, increases migration and invasion. EMT is a process in which epithelial cells lose epithelial characteristics and acquire mesenchymal properties. It is recognized as an important event in the progression and dissemination of cancer (27). MCF-10A cells cultured in hypoxia or normoxia were labeled for E-cadherin, $\beta$-catenin and vimentin using fluorescent immunohistochemistry (Fig. 4A). MCF-10A cells cultured in hypoxic conditions displayed a loss of total and membrane bound E-cadherin, a loss of total and membrane bound $\beta$-catenin (although no nuclearization was apparent) concomitant with an upregulation of vimentin expression. Collectively, these expression changes along with characteristic changes noticed in cell shape are indicative of EMT $(28,29)$. Total levels of protein expression, as detected by western blotting, confirmed global changes (Fig. 4B). Migratory and invasive capabilities are further traits acquired by cells to allow cancer metastasis (30). Scratch wound assays were used to assess the migratory ability of MCF-10A cells cultured in hypoxia vs. normoxia (Fig. 4C). MCF-10A cells cultured under hypoxic conditions displayed an increase in migratory ability. Comparative unscratched areas demonstrate highly polarized and tightly packed cells following normoxic culture conditions whilst following hypoxia, cells lose their tightly packed formation and appear more sporadic. Collectively, this suggests that wound closure is due to increased migratory abilities rather than an increase in cell number. Quantitative analysis of wound gap closure (Fig. 4D) revealed a statistically significant increase in gap closure and thus a higher rate of migration in MCF-10A cells cultured under hypoxic conditions (relative gap remaining after $48 \mathrm{~h}$ in normoxic culture conditions $0.68 \pm 0.091$ compared to $0.12 \pm 0.1$ in cells cultured under hypoxic conditions; $\mathrm{P}<0.05$ ). Higher magnification of MCF-10A cells at the leading edge of migration revealed the extent of changes in cell shape and a more 'mesenchymal/fibroblastic' appearance of cells cultured in hypoxia as opposed to normoxia (Fig. 4E). A Matrigel Transwell invasion assay was used to compare and analyze the invasive capacity of MCF-10A cells cultured in hypoxia vs. normoxia. Whilst cells cultured in normoxia displayed a limited ability to move across the Matrigel barrier, cells cultured in hypoxic conditions were readily observed on the bottom of the insert (Fig. 4F). Quantification of these cells revealed a significant increase in the number of invaded cells in cells cultured under hypoxic conditions in comparison to those cultured in normoxia (42.2 $\pm 8.57 /$ field of view compared to $0.77 \pm 0.05$ /field of view respectively; $\mathrm{P}<0.05$ ). Collectively, these results revealed that $\mathrm{O}_{2}$ deprivation in MCF-10A cells can lead to changes consistent with EMT, increased migratory ability and increased invasive capabilities.

\section{Discussion}

As metastasis is responsible for $\sim 90 \%$ of cancer-related deaths (2), underscoring the mechanisms that contribute to cancer dissemination are vital in our understanding of the disease and may thus help expose potential preventative strategies. Whilst considerable attention has been paid to the contribution of genetic and epigenetic alterations in this pathological process (5-7), the importance of tumour microenvironmental changes are beginning to be exposed (8). In the present study, we used hypoxic conditions to replicate an important microenvironmental change associated with tumourigenesis. MCF-10A cells were exposed to low $\mathrm{O}_{2}$ levels to replicate conditions found within the earlier stages of breast tumourigenesis. $\mathrm{O}_{2}$ deprivation led to some changes not immediately associated with tumourigenesis, such as decreased proliferation, cell cycle arrest and increased apoptosis. In contrast, hypoxia did induce other changes more consistent with a progression towards metastatic disease, such as an increase in 'stemness', induction of EMT and increased migratory and invasive capabilities.

Previous studies have linked hypoxia with reduced proliferation in breast cancer cell lines and ductal carcinoma in situ (31), a precursor of invasive ductal carcinoma. HIF-1 $\alpha$ expression has been observed at this early stage of breast tumour development $(31,32)$, and has been revealed to both inhibit transcription (33), and promote degradation (34) of c-MYC, an essential regulator of cellular growth and the cell cycle (35). Cell cycle progression was attenuated at the G2/M phase in our model and may represent a further mechanism for our observed reductions in proliferation. Previous studies have linked hypoxia with several G2/M checkpoint regulators and blockage of cell cycle progression at this phase $(36,37)$ and this has been reported to contribute to increased chemo- and/ or radio-resistance in some tumours $(38,39)$. The induction of apoptosis in our model may also be explained through $H I F-1 \alpha$ expression. HIF- $1 \alpha$ has previously been reported to promote apoptosis $(40,41)$. This, in part, could be explained 
by stabilization of p53 by HIF-1 $\alpha$ (42) and/or by increased transcription of HIF-1 $\alpha$ targets which are pro-apoptotic such as NIP3 (43).

Given that sustaining proliferative signaling and resisting cell death are 'hallmarks' of cancer (22), reduced proliferation, cell cycle arrest and increased apoptosis induced by hypoxia may seem disadvantageous for tumourigenesis. However, previous studies have demonstrated that hypoxia can exert a selective pressure whereby cells with accumulated genetic alterations, such as the loss of p53 (44), gain a selective advantage and constitute the tumour $(44,45)$. Furthermore, it is known that hypoxia can increase mutation frequency and lead to genomic instability (46). This is most likely due to the effects of hypoxia on the DNA damage response exerted through both HIF-1 $\alpha$ dependent (47) and HIF-1 $\alpha$ independent means (48). Collectively, these changes can lead to the generation of cells which possess the genetic and epigenetic adaptations essential for tumour progression into metastatic disease.

Hypoxia in our model also induced an increase in the stem cell population. The link between stem cells and cancer is well documented $(49,50)$, and cancer stem cells are reportedly responsible for initiating metastatic growth in various cancers including breast $(23,51,52)$. Previous studies have reported a less differentiated phenotype and/or an increase in stemness induced by hypoxia in breast tumour tissue $(31,53,54)$. Increases in stemness can, in part, be explained by the ability of HIF- $1 \alpha$ and HIF- $2 \alpha$ to induce various transcriptional programs, some of which include pluripotency factors $(55,56)$. The consequence of hypoxia-induced increases in stem cell numbers in early neoplastic lesions and the contribution of this to metastatic disease may be two-fold. First, an increase in stem cell numbers due to hypoxia along with the increased rate of mutation may increase the chance of oncogenic mutations occurring within stem cell populations leading to cancer stem cells. Second, hypoxia leading to an increase in the number of cancer stem cells may lead to an increase in metastatic potential. These reasons may contribute to why hypoxia is linked to increased metastatic disease $(13,16,17)$.

A more direct involvement of hypoxia in metastasis is elucidated from the induction of EMT observed in our model along with the increased migratory and invasive behavior of these cells. As mentioned previously, EMT is an important event in the progression and dissemination of cancer (27). Previous studies have linked hypoxia, EMT, increased migration and invasion to various cancer cell lines including breast (57-59). This most likely occurs through HIF-1 $\alpha$ - and HIF- $2 \alpha$-related transcriptional changes (60). In the present study we demonstrated that hypoxia-induced EMT, increased migratory and invasive behavior in untransformed cells. Given that metastasis occurs in the later stages of cancer progression following an accumulation of genetic and epigenetic alterations, the significance of this finding remains unclear. However, a mechanistic dissection of the roles of HIF- $1 \alpha$ and HIF- $2 \alpha$ isoforms at this early stage of transformation and the relevance of their true input warrant further investigation and should be the basis of future experiments.

To conclude, the present study provided evidence that tumour-associated microenvironmental changes have a substantial role alongside genetic and epigenetic alterations in the progression of breast cancer. Hypoxia can occur in the earliest stages of tumourigenesis and influence various cellular processes associated with metastatic potential. Although the present study uses a simplistic approach to delineate the contributions of the hypoxic microenvironment from the myriad of genetic and epigenetic alterations found in human tumours; in reality, understanding the interactions between these co-contributors may elucidate the true factors driving metastasis in human disease.

\section{Acknowledgements}

We thank Dr Muhammed Sohail at Bristol Royal Infirmary for overseeing the cataloging and processing of human breast tissue samples. We also thank Mr. David Corry, Dr Jeff Davey and Dr Natasha McGuire for their technical support and Mr. Paul Kendrick for assistance in histology.

\section{References}

1. Torre LA, Bray F, Siegel RL, Ferlay J, Lortet-Tieulent J and Jemal A: Global cancer statistics, 2012. CA Cancer J Clin 65: 87-108, 2015

2. Mehlen P and Puisieux A: Metastasis: A question of life or death Nat Rev Cancer 6: 449-458, 2006.

3. Rosen PP: Rosen's Breast Pathology. 3rd edition. LWW, pp171-242, 2008

4. Thompson A, Brennan K, Cox A, Gee J, Harcourt D, Harris A Harvie M, Holen I, Howell A, Nicholson R, et al: Evaluation of the current knowledge limitations in breast cancer research: A gap analysis. Breast Cancer Res 10: R26, 2008.

5. Vogelstein B, Papadopoulos N, Velculescu VE, Zhou S, Diaz LA Jr and Kinzler KW: Cancer genome landscapes. Science 339: 1546-1558, 2013.

6. Baylin SB and Jones PA: A decade of exploring the cancer epigenome - biological and translational implications. Nat Rev Cancer 11: 726-734, 2011

7. Network CGA; Cancer Genome Atlas Network: Comprehensive molecular portraits of human breast tumours. Nature 490: 61-70, 2012.

8. Bissell MJ and Hines WC: Why don't we get more cancer? A proposed role of the microenvironment in restraining cancer progression. Nat Med 17: 320-329, 2011.

9. Semenza GL: Targeting HIF-1 for cancer therapy. Nat Rev Cancer 3: 721-732, 2003.

10. Vaupel P, Höckel M and Mayer A: Detection and characterization of tumor hypoxia using $\mathrm{pO}_{2}$ histography. Antioxid Redox Signal 9: 1221-1235, 2007.

11. Vaupel P: Prognostic potential of the pre-therapeutic tumor oxygenation status. Adv Exp Med Biol 645: 241-246, 2009.

12. van den Beucken T, Koch E, Chu K, Rupaimoole R, Prickaerts P, Adriaens M, Voncken JW, Harris AL, Buffa FM, Haider S, et al: Hypoxia promotes stem cell phenotypes and poor prognosis through epigenetic regulation of DICER. Nat Commun 5: 5203, 2014.

13. Schindl M, Schoppmann SF, Samonigg H, Hausmaninger H, Kwasny W, Gnant M, Jakesz R, Kubista E, Birner P and Oberhuber G; Austrian Breast and Colorectal Cancer Study Group: Overexpression of hypoxia-inducible factor 1alpha is associated with an unfavorable prognosis in lymph node-positive breast cancer. Clin Cancer Res 8: 1831-1837, 2002.

14. Samanta D, Gilkes DM, Chaturvedi P, Xiang L and Semenza GL: Hypoxia-inducible factors are required for chemotherapy resistance of breast cancer stem cells. Proc Natl Acad Sci USA 111: E5429-E5438, 2014.

15. O'Reilly EA, Gubbins L, Sharma S, Tully R, Guang MH, Weiner-Gorzel K, McCaffrey J, Harrison M, Furlong F, Kell M, et al: The fate of chemoresistance in triple negative breast cancer (TNBC). BBA Clin 3: 257-275, 2015.

16. Hussain SA, Ganesan R, Reynolds G, Gross L, Stevens A, Pastorek J, Murray PG, Perunovic B, Anwar MS, Billingham L, et al: Hypoxia-regulated carbonic anhydrase IX expression is associated with poor survival in patients with invasive breast cancer. Br J Cancer 96: 104-109, 2007. 
17. Hiraga T, Kizaka-Kondoh S, Hirota K, Hiraoka M and Yoneda T: Hypoxia and hypoxia-inducible factor-1 expression enhance osteolytic bone metastases of breast cancer. Cancer Res 67: 4157-4163, 2007

18. Semenza GL: Hypoxia-inducible factors in physiology and medicine. Cell 148: 399-408, 2012.

19. Kunz M and Ibrahim SM: Molecular responses to hypoxia in tumor cells. Mol Cancer 2: 23, 2003.

20. Potter C and Harris AL: Hypoxia inducible carbonic anhydrase IX, marker of tumour hypoxia, survival pathway and therapy target. Cell Cycle 3: 164-167, 2004.

21. Höckel M and Vaupel P: Tumor hypoxia: Definitions and current clinical, biologic, and molecular aspects. J Natl Cancer Inst 93: 266-276, 2001.

22. Hanahan D and Weinberg RA: Hallmarks of cancer: The next generation. Cell 144: 646-674, 2011.

23. Al-Hajj M, Wicha MS, Benito-Hernandez A, Morrison SJ and Clarke MF: Prospective identification of tumorigenic breast cancer cells. Proc Natl Acad Sci USA 100: 3983-3988, 2003.

24. Ghebeh H, Sleiman GM, Manogaran PS, Al-Mazrou A, Barhoush E, Al-Mohanna FH, Tulbah A, Al-Faqeeh K and Adra CN: Profiling of normal and malignant breast tissue show $\mathrm{CD} 44^{\text {high }} / \mathrm{CD} 24^{\text {low }}$ phenotype as a predominant stem/progenitor marker when used in combination with Ep-CAM/CD49f markers. BMC Cancer 13: 289, 2013.

25. Dontu G, Abdallah WM, Foley JM, Jackson KW, Clarke MF, Kawamura MJ and Wicha MS: In vitro propagation and transcriptional profiling of human mammary stem/progenitor cells. Genes Dev 17: 1253-1270, 2003.

26. Diaz-Guerra E, Lillo MA, Santamaria S and Garcia-Sanz JA: Intrinsic cues and hormones control mouse mammary epithelial tree size. FASEB J 26: 3844-3853, 2012.

27. Thiery JP: Epithelial-mesenchymal transitions in tumour progression. Nat Rev Cancer 2: 442-454, 2002.

28. Blanco D, Vicent S, Elizegi E, Pino I, Fraga MF, Esteller M, Saffiotti U, Lecanda F and Montuenga LM: Altered expression of adhesion molecules and epithelial-mesenchymal transition in silica-induced rat lung carcinogenesis. Lab Invest 84: 999-1012, 2004.

29. Yoshida R, Kimura N, Harada Y and Ohuchi N: The loss of E-cadherin, $\alpha$ - and $\beta$-catenin expression is associated with metastasis and poor prognosis in invasive breast cancer. Int $\mathrm{J}$ Oncol 18: 513-520, 2001.

30. Friedl $\mathrm{P}$ and Wolf $\mathrm{K}$ : Tumour-cell invasion and migration: Diversity and escape mechanisms. Nat Rev Cancer 3: 362-374, 2003.

31. Helczynska K, Kronblad A, Jögi A, Nilsson E, Beckman S, Landberg G and Påhlman S: Hypoxia promotes a dedifferentiated phenotype in ductal breast carcinoma in situ. Cancer Res 63: 1441-1444, 2003.

32. Bos R, Zhong H, Hanrahan CF, Mommers EC, Semenza GL, Pinedo HM, Abeloff MD, Simons JW, van Diest PJ and van der Wall E: Levels of hypoxia-inducible factor-1 alpha during breast carcinogenesis. J Natl Cancer Inst 93: 309-314, 2001

33. Koshiji M, Kageyama Y, Pete EA, Horikawa I, Barrett JC and Huang LE: HIF-1alpha induces cell cycle arrest by functionally counteracting Myc. EMBO J 23: 1949-1956, 2004.

34. Zhang H, Gao P, Fukuda R, Kumar G, Krishnamachary B, Zeller KI, Dang CV and Semenza GL: HIF-1 inhibits mitochondrial biogenesis and cellular respiration in VHL-deficient renal cell carcinoma by repression of C-MYC activity. Cancer Cell 11: 407-420, 2007.

35. Schmidt EV: The role of c-myc in cellular growth control. Oncogene 18: 2988-2996, 1999.

36. Amellem O, Löffler M and Pettersen EO: Regulation of cell proliferation under extreme and moderate hypoxia: The role of pyrimidine (deoxy)nucleotides. Br J Cancer 70: 857-866, 1994.

37. Hasvold G, Lund-Andersen C, Lando M, Patzke S, Hauge S, Suo Z, Lyng H and Syljuåsen RG: Hypoxia-induced alterations of G2 checkpoint regulators. Mol Oncol 10: 764-773, 2016.

38. Sullivan R, Paré GC, Frederiksen LJ, Semenza GL and Graham CH: Hypoxia-induced resistance to anticancer drugs is associated with decreased senescence and requires hypoxiainducible factor-1 activity. Mol Cancer Ther 7: 1961-1973, 2008.

39. Wouters A, Pauwels B, Lardon F and Vermorken JB: Review: Implications of in vitro research on the effect of radiotherapy and chemotherapy under hypoxic conditions. Oncologist 12: 690-712, 2007.
40. Carmeliet P, Dor Y, Herbert JM, Fukumura D, Brusselmans K, Dewerchin M, Neeman M, Bono F, Abramovitch R, Maxwell P, et al: Role of HIF-1alpha in hypoxia-mediated apoptosis, cell proliferation and tumour angiogenesis. Nature 394: 485-490, 1998.

41. Volm M and Koomägi R: Hypoxia-inducible factor (HIF-1) and its relationship to apoptosis and proliferation in lung cancer. Anticancer Res 20: 1527-1533, 2000.

42. Ravi R, Mookerjee B, Bhujwalla ZM, Sutter CH, Artemov D, Zeng Q, Dillehay LE, Madan A, Semenza GL and Bedi A: Regulation of tumor angiogenesis by p53-induced degradation of hypoxia-inducible factor lalpha. Genes Dev 14: 34-44, 2000.

43. Bruick RK: Expression of the gene encoding the proapoptotic Nip3 protein is induced by hypoxia. Proc Natl Acad Sci USA 97: 9082-9087, 2000.

44. Graeber TG, Osmanian C, Jacks T, Housman DE, Koch CJ, Lowe SW and Giaccia AJ: Hypoxia-mediated selection of cells with diminished apoptotic potential in solid tumours. Nature 379: 88-91, 1996.

45. Semenza GL: Hypoxia, clonal selection, and the role of HIF-1 in tumor progression. Crit Rev Biochem Mol Biol 35: 71-103, 2000.

46. Reynolds TY, Rockwell S and Glazer PM: Genetic instability induced by the tumor microenvironment. Cancer Res 56: 5754-5757, 1996.

47. Sendoel A, Kohler I, Fellmann C, Lowe SW and Hengartner MO: HIF-1 antagonizes p53-mediated apoptosis through a secreted neuronal tyrosinase. Nature 465: 577-583, 2010.

48. Bindra RS and Glazer PM: Genetic instability and the tumor microenvironment: Towards the concept of microenvironmentinduced mutagenesis. Mutat Res 569: 75-85, 2005.

49. Clevers H: The cancer stem cell: Premises, promises and challenges. Nat Med 17: 313-319, 2011.

50. Visvader JE and Stingl J: Mammary stem cells and the differentiation hierarchy: Current status and perspectives. Genes Dev 28: $1143-1158,2014$.

51. Oskarsson T, Batlle E and Massagué J: Metastatic stem cells: Sources, niches, and vital pathways. Cell Stem Cell 14: 306-321, 2014.

52. Velasco-Velázquez MA, Popov VM, Lisanti MP and Pestell RG: The role of breast cancer stem cells in metastasis and therapeutic implications. Am J Pathol 179: 2-11, 2011.

53. Keith B and Simon MC: Hypoxia-inducible factors, stem cells, and cancer. Cell 129: 465-472, 2007.

54. Conley SJ, Gheordunescu E, Kakarala P, Newman B, Korkaya H, Heath AN, Clouthier SG and Wicha MS: Antiangiogenic agents increase breast cancer stem cells via the generation of tumor hypoxia. Proc Natl Acad Sci USA 109: 2784-2789, 2012.

55. Mathieu J, Zhang Z, Nelson A, Lamba DA, Reh TA, Ware C and Ruohola-Baker H: Hypoxia induces re-entry of committed cells into pluripotency. Stem Cells 31: 1737-1748, 2013.

56. Zhang C, Samanta D, Lu H, Bullen JW, Zhang H, Chen I, He X and Semenza GL: Hypoxia induces the breast cancer stem cell phenotype by HIF-dependent and ALKBH5-mediated $\mathrm{m}^{6} \mathrm{~A}$-demethylation of NANOG mRNA. Proc Natl Acad Sci USA 113: E2047-E2056, 2016.

57. Muñoz-Nájar UM, Neurath KM, Vumbaca F and Claffey KP: Hypoxia stimulates breast carcinoma cell invasion through MT1-MMP and MMP-2 activation. Oncogene 25: 2379-2392, 2006.

58. Krishnamachary B, Zagzag D, Nagasawa H, Rainey K, Okuyama H, Baek JH and Semenza GL: Hypoxia-inducible factor-1-dependent repression of E-cadherin in von Hippel-Lindau tumor suppressor-null renal cell carcinoma mediated by TCF3, ZFHX1A, and ZFHX1B. Cancer Res 66: 2725-2731, 2006.

59. Lester RD, Jo M, Montel V, Takimoto S and Gonias SL: uPAR induces epithelial-mesenchymal transition in hypoxic breast cancer cells. J Cell Biol 178: 425-436, 2007.

60. Semenza GL: The hypoxic tumor microenvironment: A driving force for breast cancer progression. Biochim Biophys Acta 1863: 382-391, 2016.

This work is licensed under a Creative Commons Attribution-NonCommercial-NoDerivatives 4.0 International (CC BY-NC-ND 4.0) License. 